\section{Geometrical Perspective}

C onnections between mathematics and the visual arts have been evident since earliest times. A notable feature of Renaissance painting was that, for the first time, artists became interested in depicting three-dimensional objects realistically, giving visual depth to their works. This led to the study of geometrical perspective.

The first artist to investigate perspective seriously was the artisan-engineer Filipo Brunelleschi, who designed the selfsupporting octagonal cupola of Florence cathedral. His ideas were developed by his friend Leon Battista Alberti (1404-1472), who presented mathematical rules for correct perspective painting, stating in his Della Pittura [On Painting] that "the first duty of a painter is to know geometry."

Piero della Francesca (1415-1492) found a perspective grid useful for his geometrical investigations, and wrote De Prospectiva Pingendi [On the Perspective of Painting] and Libellus de Quinque Corporibus Regularibus [Book on the Five Regular Solids]. His Madonna and Child with Saints (1472) is in perfect mathematical perspective.

The other title on these stamps is De Divina Proportione [On Divine Proportion] (1509) by Piero's friend Luca Pacioli (1445-1517). The woodcuts of polyhedra in this book were by his friend and student Leonardo da Vinci (1452-1519), who explored perspective more deeply than any other Renaissance painter. In his Trattato Della Pittura [Treatise on Painting] da Vinci warns "Let no one who is not a mathematician read my work."

The celebrated German artist and engraver Albrecht Dürer (1471-1528) learned perspective from the Italians and introduced it to Germany. His famous engravings, such as St Jerome in His Study, show his effective use of perspective.

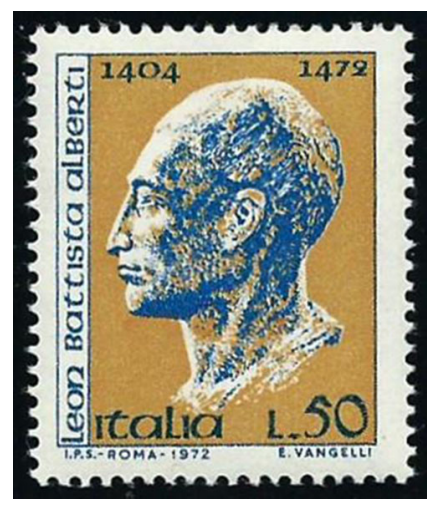

Alberti

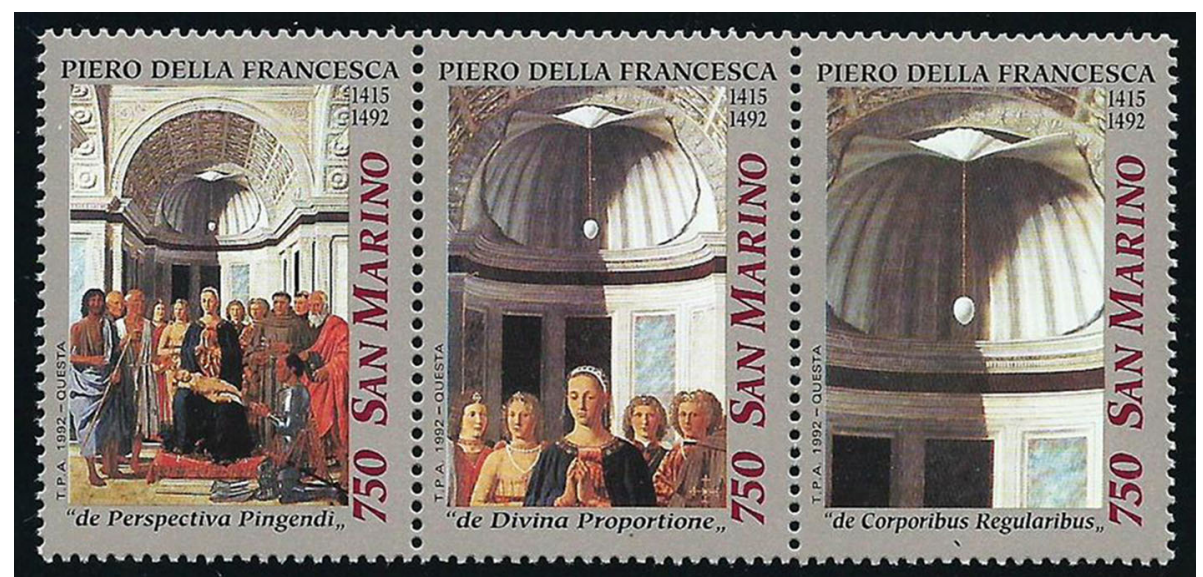

Madonna and Child

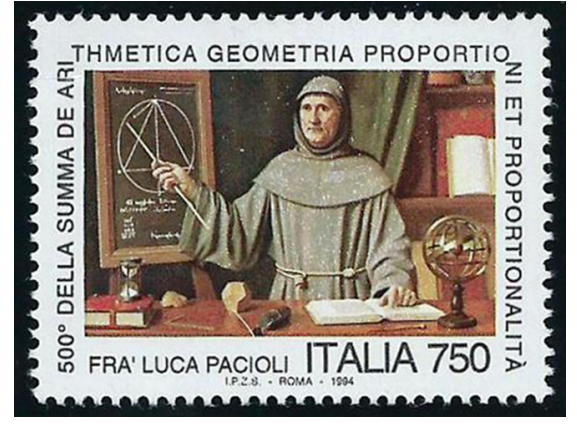

Luca Pacioli

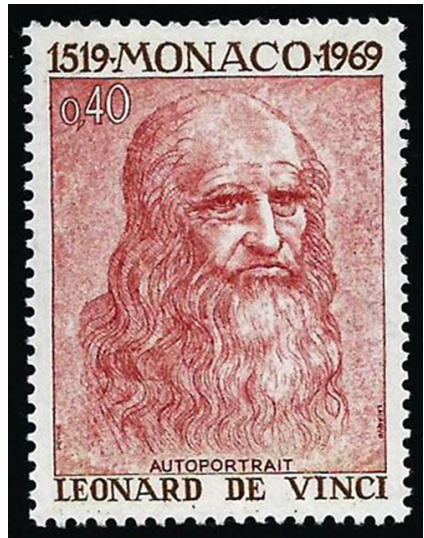

da Vinci

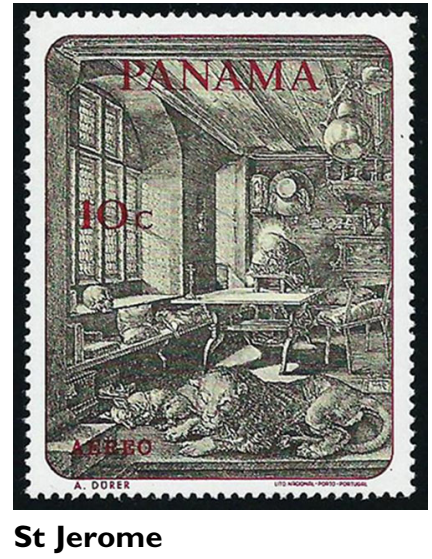

> Column editor's address: Robin Wilson, Pembroke College, 